\title{
Mushrooms and Lichens in Bulgarian Ethnomycology
}

\author{
Blagoy Angelov Uzunov and Maya Petrova Stoyneva-Gärtner \\ Department of Botany, Faculty of Biology, Sofia University "St. Kliment Ohridski”, 8 Boulevard Dragan Tsankov, \\ 1164 Sofia, Bulgaria \\ Correspondence should be addressed to Blagoy Angelov Uzunov; blagoy_uzunov@abv.bg
}

Received 31 August 2015; Accepted 19 October 2015

Academic Editor: Leo Van Griensven

Copyright ( 2015 B. A. Uzunov and M. P. Stoyneva-Gärtner. This is an open access article distributed under the Creative Commons Attribution License, which permits unrestricted use, distribution, and reproduction in any medium, provided the original work is properly cited.

\begin{abstract}
The paper presents ethnomycological data on ritual, medicinal, tinder, and kindling usage of mushrooms and lichens in Bulgaria from prehistoric times till nowadays. It is based on the analysis of 17 ethnomycological sources recently available and on the authors inquiries and field trip data from the country made in the period 1986-2015. In total 18 mushrooms and 4 lichens with their usage are enlisted.
\end{abstract}

\section{Introduction}

The study of fungi in folklore and rituals, from prehistoric times to the present days, comprises the science of ethnomycology [1], to which the first main contributions are given by V. P. Wasson and R. G. Wasson [2], Heim et al. [3], and Wasson [4, 5]. Ethnomycological studies have so far been very rarely conducted in Europe (e.g., [2, 6-15]). V. P. Wasson and R. G. Wasson [2] included Bulgaria in their ethnomycological studies on the role of mushrooms in the daily lives of different European people. Nevertheless that the authors noted only the meaning of the chanterelle (Cantharellus cibarius Fr.) name in Bulgarian language ("duck leg"), the work of V. P. Wasson and R. G. Wasson [2] remains the only known glimpse on Bulgarian ethnomycology. The first comprehensive ethnobotanical paper, published in Bulgaria on traditional uses of lichens, presented data on their significance, primarily as food resources, from all over the world, without mentioning Bulgaria [16]. More recently, the knowledge on mushrooms used for food and changes in food habits of Bulgarian people due to globalization were summarized by [17]. The purpose of the present paper is to provide more information related to other usage of fungi (incl. lichens) in Bulgaria since ancient times to nowadays.

\section{Materials and Methods}

This study compiles and evaluates the ethnomycological data currently available from 17 sources [18-34] related with the recent territory of Bulgaria (Figure 1).

Fungal (incl. lichen) names are given according to Index Fungorum [35], and lichen names are checked also after Wirth et al. [36].

Field studies on the use of fungi were conducted by the authors in the years 1986-2015 during their scientific field trips and student summer practices in the country. Our students were also inquired and were asked to mention all fungal species and products, which were used by them or their parents and relatives. Ethical guidelines drafted by the International Society of Ethnobiology [37] and American Anthropological Association [38] were followed.

\section{Results and Discussion}

3.1. Hallucinogenic Fungi: Use of Mushrooms as Entheogens and Recreational Drugs. The first mention of hallucinogenic mushrooms in European medicinal literature concerned Psilocybe semilanceata (Fr.) P. Kumm. and appeared in 1799 [39]. According to [40] and citations therein, the references on their use in the New World could be found much earlier 


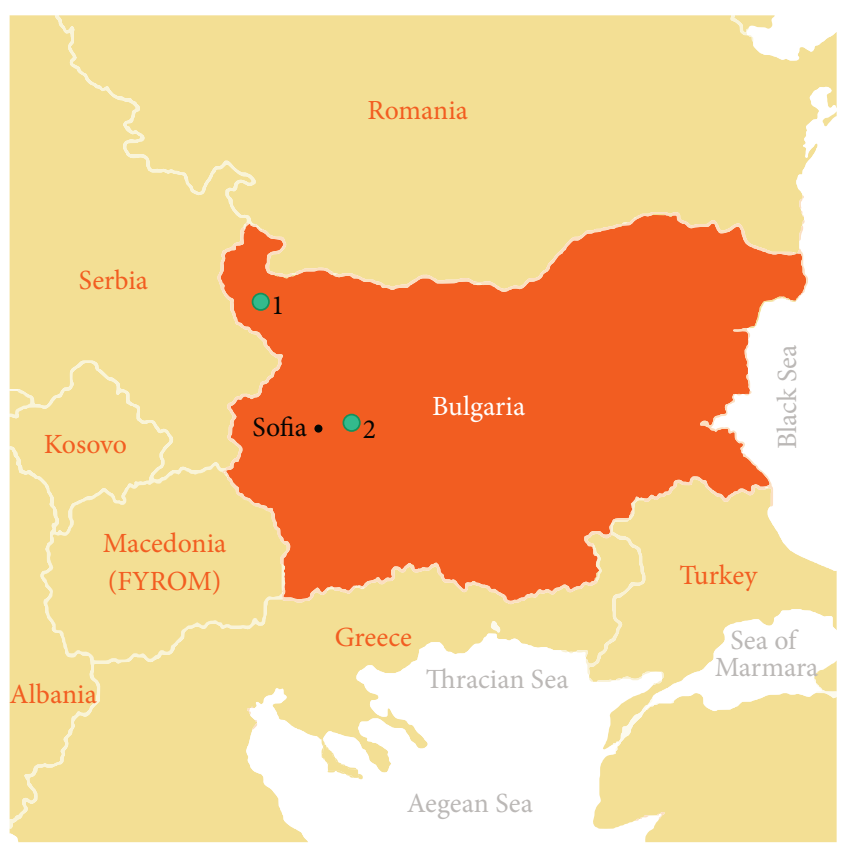

Figure 1: Map of Bulgaria (after http://balkans360.com/tag/europe/) with indication of the location of the cave Magurata (1) and the cave No. 2961 (2), in which the ancient fungal ideograms and paintings have been found.

(e.g., [41, 42]), but only after the studies of Schultes [43] and Heim [44], the very attractive article of Wasson [45] opened the magic world of hallucinogenic fungi to a wide readership and provoked publication of numerous articles and books all over the world. Thus the use of hallucinogenic mushrooms, known variably as entheogenic, magic, medicinal, neurotropic, psychedelic, psychoactive, sacred, saint, or visionary mushrooms [46] and schrooms [47], became quite well documented. However, yet the evidence concerning prehistoric ritual use of fungi as entheogens is scant. Their world oldest representations were found from the Paleolithic period in the Sahara Desert (9000-7000 B.P. [48]), while the most ancient example from prehistoric Europe is the Neolithic rock art from the Spanish cave Selva Pascuala 6, 000 years ago (for details, see [13] and citations therein). According to our search, on the territory of Bulgaria the use of mushrooms as entheogens dates back to the Neolithic and Bronze Age $[18,19]$. This knowledge is based on the unique murals discovered in the cave Magurata (Vidin district) and in the cave No. 2961, situated near to the village Baylovo (Sofia district).

The exact chronology of the Magurata paintings is still unknown $[29,49]$, whereas the paintings in cave 2961 date back to the beginning of the Bronze Age 3000 B.C. $[28,29]$. In Magurata cave more than 750 darkish figures have been counted, situated alone, side by side or arranged in scenes. They were made with bat guano, smeared or rubbed in multiple layers along the cave walls [50]. Figure 2 represents a part of one of the longest multilayered frieze from cave Magurata, where the greatest number of human images, their attributes, and two mushrooms can be seen. There is

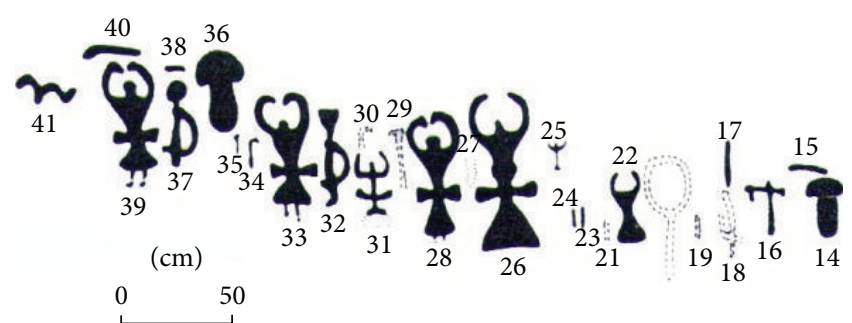

Figure 2: A part of a multilayer frieze from the cave Magurata. The composition represents an ideogram of a mystery with ithyphallic scenes and mushroom, which contains psychedelic substances (after [19]).

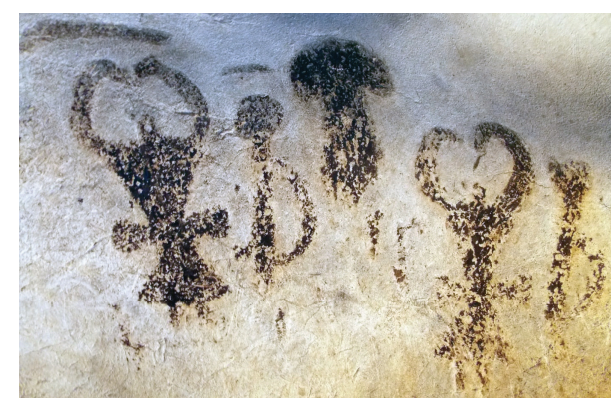

FIGURE 3: Ithyphallic scenes and fungus from cave Magurata, guano paintings (after [28] and https://posveshtenie.wordpress.com).

an interesting group of related ithyphallic scenes (Figure 3), deciphered from the right to the left $[29,51]$. The ithyphallic pairs (Figure 3) are most probably two artistic expressions of the same character in concrete form with relevant personal attributes (the right pair).

Under the influence of hallucinogenic substances the characters pass into a qualitatively new symbolic form, in close contact with Gods (the left pair). There the personal attributes are depicted on their heads in the same level with the fungus [23]. The painting of another fungus is presented with a horizontal sign over it. This connects the fungus with schematically indicated scepter, a symbol of power. In Bulgarian lands, according to [28,39], secret celebrations or mysteries were performed and in one of them a hallucinogenic drug taken from a fungus had been used. Due to the fact that in religious rites the image of the mushroom is given twice (numbers 14 and 36 in Figure 2) it is possible to claim the great importance of this practice. The admittance of the significance of the mushrooms comes from the fact that the fungal sizes are almost equal with these of men's figures from ithyphallic scenes in the frame of the interpretation that the sizes of drawings are related with their importance in the imaged events [28]. A similar scene appears in another frieze from Magurata cave (Figure 4). However, separately from the ithyphallic pair, there is a painted symbol of a horn, which possibly contains a divine drink. A painting of the right profile of male figure, which holds in his outstretched hand a horn, was found in cave No. 2961 (Figure 5). This is an obvious parallel with the paintings from the leakages friezes in Magurata cave, where the fungus is also presented 


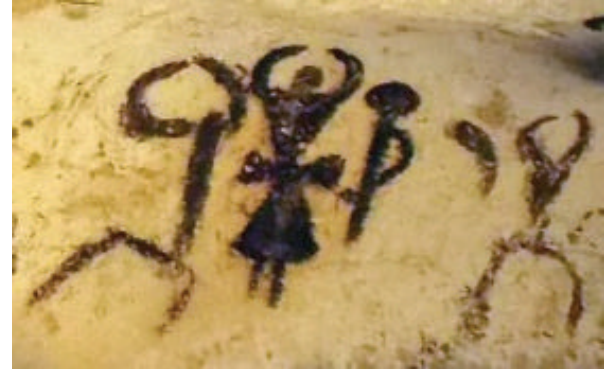

FIGURE 4: Guano painting from cave Magurata, in which separately from the ithyphallic pair there is a painted symbol of a horn, which possibly contains a divine drink (after $[28,29]$ and https://posveshtenie.wordpress.com).

at the right side (Figure 6). In the last case, the man passed to the priestess a horn, which probably contains an extract of the fungus [28]. On the base of fungal morphology (shape), after consultations with S. Dimitrova, Guerassimova and Stoytchev [28] and Stoytchev and Gerassimova [29] reported that the mushroom from the cave paintings in Magurata may be identified as the species Suillellus luridus (Schaeff.) Murrill (Syn.: Boletus luridus Schaeff.), the Lurid bolete. They also concluded with certainty that the ceremonies with ithyphallic scenes, depicted in Magurata cave, took place from May till October, the period of mushrooms growth under the local climatic conditions. The last authors, based on the data of R. Daskalov, provided also information about the different substances in the fruiting bodies of Suillellus luridus: muscarine with hallucinogenic drug effect, atropine with impact on the psyche and sexually arousing effect, and bufotenine with impact on the psychics. Taking into account that (1) the chemical analysis of $S$. luridus has revealed only traces of the toxin muscarine and its stereoisomers [52], (2) muscarine in this fungus is found together with a toxic gastrointestinal irritant [53], and (3) the species is known and used as edible mushroom in the country (after boiling [54]), the authors of the recent paper have some doubts in this determination down to species level. However, a detailed discussion runs out of the scope of the present study and will be published elsewhere. In any case, according to the murals found, the prehistoric use of some mushrooms as entheogens on the territory of the country is doubtless.

By contrast, the usage of mushrooms as kind of recreational drugs from people living on the territory of Bulgaria was generally rare and remained almost not documented. According to the written sources, only Amanita muscaria (L.) Lam. (fly agaric or fly amanita) and Amanita pantherina (DC.) Krombh. (panther cap or false blusher) have been taken for such purposes by ingesting of one middle-sized dry fruiting body as a traditional hallucinogenic dose [31]. Rarer, and mainly during the last decades, attempts to smoke dry fungal material from A. muscaria, owned up mainly by some youths, were registered [31]. Another possible way to use the fly amanita is to prepare a water decoction, but in this case for the obtaining of a hallucinogenic effect it is necessary to drink a big amount of liquid [31]. During our inquiries

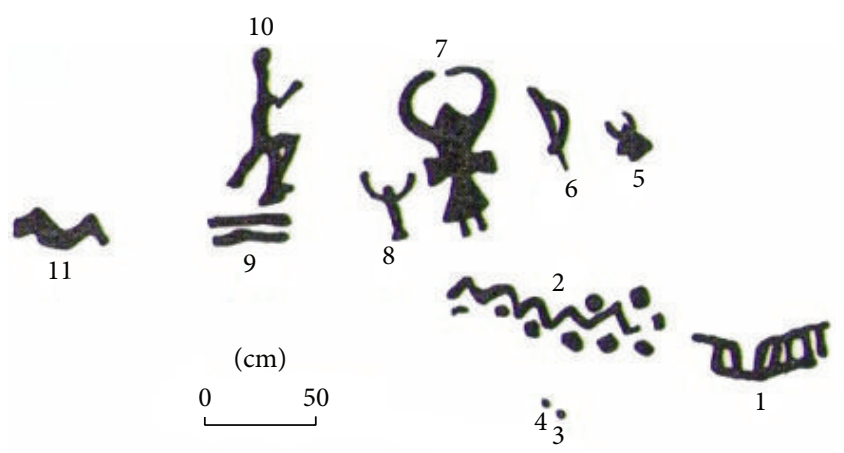

FIGURE 5: Part of ideograms from cave No. 2961 with the right profile of male figure, which holds in his outstretched hand a horn (after $[28,29])$.

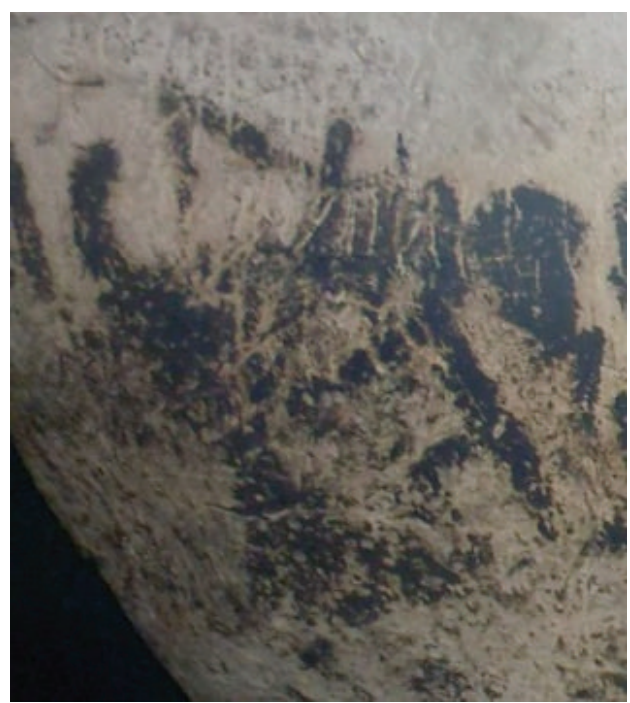

FIgURE 6: Guano painting from cave Magurata with fungus and male figure, which serves horn to the priestess (after [28] and https://posveshtenie.wordpress.com).

with students, even the mentioning of the ritual consecutive urine drinking after the first person (usually the "shaman") has ingested the mushroom, well known from eastern Siberia and contradictively pointed for India [31, 55-58], makes them react negatively and it is difficult to believe that such way of fungal use has been followed by Bulgarians. Our inquiries with older people ( $>60$ years) in the country lead mainly to the answer that the fungus is "deadly poisonous" and is generally avoided by them.

Probably nowadays the most often used fungal species with hallucinogenic effect by young Bulgarians (age of 1525 years) is Psilocybe semilanceata (Fr.) P. Kumm (Liberty Cap). It is native for the country but became "famous" among Bulgarian youths in the last $10-15$ years. The species is typical for the mountain areas in the country (Rila Mt., Pirin Mt., Strandzha Mt.) [59]. However, its distribution in no way impedes lovers of magic mushrooms and just in opposite stimulates them to travel and to look for their own 
hallucinogenic fungus between grasses in the mountains. This so called drug-tourism became very popular among Bulgarian youths. Sometimes in Bulgarian news interesting comments and articles related to the Psilocybe semilanceatahunters appear: "...young people creeped up the slope with lazy speed with which cows graze on lush grass. Everybody who picked fungus, beware. They beware not only from curious amateurs, who do not know these mushrooms, but also from other pickers. They can always explain that they pick herbs or something else. They keep mostly from the competition. Each (collector) has his own territory which he does not concede to anyone else. So, you will see companies that come here camping, but when there are not many people around, they pick mushrooms. In mornings they go first, before tourists slide the pathways and check what has "sprouted." Rarely do they eat them immediately. They collect them and everyone tries to be the first to "rob" the field because mushrooms are not quite in such abundance, while pickers are many..." [32]. "This is the coolest way to highs - there in the nature, not closed in any apartment" said Georgi S., 19-year-old citizen of Sofia city (the Capital of Bulgaria [33]). There are people who eat hallucinogenic fungi row and directly on the mountain meadows. The usual hallucinogenic dose is $20-25$ fruiting bodies but sometimes mushrooms lovers ingest a double dose of 50 to achieve a stronger effect. Commonly this fungus is used dry as whole fruiting bodies (cap and stem), or powdered. In the last case, the hallucinogenic dose for "beginners" is $1 \mathrm{~g}$ and for those with experience it is $2 \mathrm{~g}$ [33]. Some people do not like the taste of the fungus and ingest it together with honey, which serves also as a conservation agent for the dried fruiting bodies. Toxins in Psilocybe semilanceata, which cause hallucinations, are psilocybin and baeocystin [60,61]. Other hallucinogenic species of genus Psilocybe (Fr.) P. Kumm. used in Bulgaria are the exotic P. azurescens Stamets and Gartz, P. cubensis (Earle) Singer, P. cyanescens Wakef., and P. mexicana R. Heim. They contain the toxin psilocin in addition to psilocybin $[60,61]$. Nowadays it is very modern to grow them at home and many people buy spores from abroad through Internet in order to cultivate their own, "homemade" hallucinogenic fungal material.

3.2. Medicinal Fungi. In Bulgarian folk medicine, according to the analysis of summarized data [18-23,34], mainly the representatives of the sac fungi (Ascomycota) have been used, whereas basidial species (Basidiomycota) achieved less attention. Below, the mostly utilized mushrooms and lichens and their main medicinal applications are enlisted.

From the sac fungi, the lichens (lichenized fungi) are the most used and among them Cetraria islandica (L.) Ach. (true Iceland lichen, Iceland moss, usually termed in pharmacopeias Lichen islandicus and known as "Islandski Lishey" in Bulgarian language and as "Iceland lichen" in English) is mentioned most often in different recipes. Iceland moss is widespread in moist shady meadows, pastures, rocky places, or coniferous forests above 1500 meters altitude in all Bulgarian mountains [62]. People collect the entire lichen thallus during the whole year, but mainly during the summer. The collected material is drying in ventilated rooms or in a drying oven (up to $60^{\circ} \mathrm{C}$ ) and after that it is stored in a dry and ventilated place away from direct sunlight. For internal use the "Iceland lichen" is applied mainly in cases of stomach and respiratory tract problems, against cough, and for excitation of the appetite [22,23]. For external use it is recommended for the festering wounds and burns. In the recipes provided by Dimkov [18-21] the Iceland moss is used for treatment of broad palette of different diseases and prepared as decoction, tea, or syrup.

A water decoction of Iceland moss was recommended for treatment of Grave's disease (Morbus Basedowi, exophthalmic goitre) [34].

In decoctions, prepared together with other herbs, the Iceland moss is used in cases of accelerated sedimentation of RBCs, acne, acromegaly, acute pancreatitis, Addison's disease, adenoid growth of the thyroid gland, adrenal gland cancer, adrenal gland hypofunction, advanced heart, albino children, alopecia, altitude sickness, anemia, angina pectoris, angioma, ankylosing spondylitis, ankylosis, arachnoiditis, arrhythmia, arteritis, asthma, blepharitis, blisters on the face and body, bone and joint tuberculosis, bone thinning substance, breaking the hips, breast cancer, bronchiectasis, bronchitis, cardiac asthma, catarrhal stomatitis, cerebral embolism, chronic atrophic rhinitis, chronic constipation, cirrhosis, combat aging, congenital heart disease, critical age with a rush of blood to the head, cryptorchidism, curvature of the spine (humps), cutaneous tuberculosis, dandruff, death of young babies of a mother at the same time (of the same age), deforming osteoporosis, damage and tear of joint cartilage, diabetes insipidus, diarrhea, disease of the spleen (inflamed, enlarged), drooping eyelids, dry mouth, Duhring disease, dumbness, duodenal ulcer, Dupuytren's contracture, dysentery, elephantiasis, emaciation, endocarditis, endometritis, enlarged heart, epididymitis, erythremia, erysipelas, excessive growth in children, excessive hair growth, exudative skin rash with serous purulent or hemorrhagic content, facial wrinkles, flatfoot, fragile and weak bones, freckles, gangrene, glaucoma, goitre, gout, graying of hair, Graves' disease, gynecomastia, hard healing cracked and broken bone, hard salivation, headache, haemophilia, heart failure (with or without temperature), heaviness in the stomach, hives, Hodgkin's disease, hot flushes, hypermetropia, hypotension, impotence, increasing the growth of the body with 10$15 \mathrm{~cm}$, infertility from oviduct scarring of the tubes, inflamed and enlarged third tonsil, inflammation of Bartholin's gland, inflammation of lymph nodes, inflammation of the lacrimal duct, inflammation of the lymph vessels, inflammation of the urinary tract, intestinal pain, itching on the body and nervous heart, late developing children, keratitis, keratoconus, leukemia, lipoma (wen), Little's disease, lymphangioma, lymphomas, male infertility, mastitis, Mediterranean anemia, melancholy, mole skin, mumps in children, muscular rheumatism, myocarditis, myxedema, nasal polyps, nearsightedness, nephrosclerosis, nervous heart, neurosis solar plexus, nyctalopia, obesity, onanism, oophoritis, osteomyelitis, osteonecrosis, ovarian tuberculosis, pemphigus, periostitis, poliomyelitis, polyarthritis, polyneuritis, profuse sweating, progressive muscular dystrophy, progressive muscular atrophy (drying), prostate gland stones, psoriasis, pulmonary 
abscess, pulmonary heart, pulmonary tuberculosis, purpura, pyorrhea, Raynaud's disease, red nose, reduced amount of platelets in the blood, reduced hemoglobin, renal tuberculosis, rheumatic purpura, rickets (English disease), rotting of the jaw bones, salivary stones, scarring of the pleura, scarlet fever in children, scleroderma, sclerotic nails, scrofula, seborrhea, seborrheic eczema, seizures in children, senile dementia, sepsis, shingles, short stature in children, sings of trauma or burning, sinusitis, skin itching, sleeping sickness (lethargic encephalitis), softening (distortion) of the bone, spleen cancer, splenitis, sticking pericarditis, stomach ulcer, strabismus, subcutaneous nodular tuberculosis, swallowing air when eating, sweating of the hands and feet, swollen feet, tachycardia, testicular tuberculosis, tetany, thyrotoxicosis, tinea, transverse myelitis, tubercular cough, TB external lymph nodes, TB hip, TB joints, TB lymph nodes, tuberculous peritonitis, tuberculous spondylitis, underdeveloped and sagging breasts, unpleasant body odor due to excessive sweating, uremia, vitiligo, vomiting, warts and chicken thorn, wet eczema, withdrawal from smoking in severe cases, whitening of the cornea, whooping cough, and yellowing of palms and soles [18-21, 34].

Tea from the lichen is used in cases of dry ear canal (insufficient separation of earwax), seborrhea, poor memory, and distraction. Syrup from the lichen is applied for treatment of chronic enteritis and enterocolitis [18-21].

Some people follow the recipes of folk medicine, but the medicinal properties of this lichen are used by modern Bulgarian people mainly as herbal cough remedy. During the last ca. 25 years, different types of Icelandic moss-based pastilles (e.g., Isla Classis, Isla Mint, and Isla Moos) became popular in the country.

The second popular lichen is Evernia prunastri (L.) Ach. (oakmoss, known with the same meaning of the name in Bulgarian language as "Dubov muh"). It is widespread on the oak bark and many other deciduous trees and shrubs in forests and fields of Bulgaria [62]. People collect the entire lichen thallus during the whole year, but mainly in early spring (March-April) or in autumn (October-November). The collected material is drying in ventilated rooms or in a drying oven (up to $55^{\circ} \mathrm{C}$ ) and after that it is stored in a dry and ventilated place away from direct sunlight. In Bulgarian folk medicine the lichen thallus is used for excitation of the appetite, as softener in chronic constipation and in cases of cough and asthma [22, 23].

In addition to its medicinal use, the lichen is mentioned as a well-known source for perfumery substances and compounds [22].

The third lichen, mentioned in Bulgarian folk medicine, is Usnea barbata (L.) F.H. Wigg (Old Man's Beard, known in Bulgarian language as "Bradat Lishey" and as "Bearded Lichen" in English). It is widespread in mountains areas of the country, growing epiphytically on the bark of deciduous and coniferous trees [62]. The lichen thallus is used for treatment of stomach pains, tuberculosis, cough, and asthma and for excitation of the appetite as well [23]. Due to the fact that species of the lichen genus Usnea Nyl. are difficult to be distinguished by amateurs and especially when they are found in the field without fruiting bodies [63], it is possible to suggest that practically different species of "bearded lichens" are mentioned in Bulgarian folk medicine recipes.

Lobaria pulmonaria (L.) Hoffm. (tree lungwort, lung lichen, lung moss, lungwort lichen, oak lungs, or oak lungwort, known in Bulgarian language as "Belodroben lishey" which means exactly lung lichen) has a very peculiar shape that somewhat resembles the tissue inside lungs and therefore based on the the doctrine of signatures (The doctrine of signatures, dating from the time of Dioscorides and Galen, states that herbs that resemble various parts of the body can be used by herbalists to treat ailments of those parts of the body), it is a worldwide known medicinal lichen, thought to be a remedy for lung diseases [64]. Surprisingly, this spread in Bulgaria lichen [62] is not mentioned in our ethnomycological sources available. The only documentation for its curative usage in the country is given briefly in the maintenance of the proposal for protection of this species by Bulgarian conservation legislation [30]. Nowadays, the medicinal properties of the lichen are "rediscovered" by modern Bulgarians due to the broad advertisement and usage of the homeopathic anticough syrups (e.g., different Stodal types), based on the lichen (enlisted in the remedial description with its older name Sticta pulmonaria). It has to be mentioned that almost all students and town people inquired have heard the name of this type of syrup and know that it relieves (both dry and wet) coughs, but nobody answered positively when asked if he knows that among the compounds there is a lichen included.

Much less in Bulgarian folk medicine is the usage of basidiomycetous fungi or it is much less documented. It is generally limited to the broadly known by local people application of the basidiospores of Bovista spp. on skin wounds for their rapid healing. However, according to our observations and inquiries, in the last 10 years, Bulgarians began to use for medicinal purposes many new fungal products (pills, powder, extracts, vaseline, etc.) due to their appearance on the market and broad advertisements in popular newspapers, woman and home journals, TV, and Internet and increasing popularity of fungotherapy (e.g., [27]). These new products contain the basidiomycetes Ganoderma lucidum (Curtis) P. Karst. (Reishi), Grifola frondosa (Dicks.) Gray (Maitake), Lentinula edodes (Berk.) Pegler (Shiitake), Ophiocordyceps sinensis (Berk.) G. H. Sung, J. M. Sung, Hywel-Jones, and Spatafora (Syn.: Cordiceps sinensis (Berk.) Sacc.; Cordyceps), Inonotus obliquus (Ach. ex Pers.) Pilát., Agaricus blazei Murrill, Trametes versicolor (L.) Lloyd (Syn.: Polyporus versicolor (L.) Fr., Coriolus versicolor (L.) Quél.), Hericium erinaceus (Bull.) Pers., and Piptoporus betulinus (Bull.) P. Karst. Paradoxically; some of these products have very high prices and are imported, although the fungi are common in Bulgarian nature (Piptoporus betulinus, Inonotus obliquus, and Trametes versicolor [59]).

3.3. Fungi Used as Kindling and Tinder. This group comprises mainly xylotrophic basidiomycetes which form large enough fruiting bodies, and the most used among them is Fomes fomentarius (L.) Fr. (tinder fungus, false tinder fungus, hoof fungus, tinder conk, tinder polypore, or ice man fungus). In spite of the fact that the Bulgarian name of this macromycete 
is "Prahan," which means "tinder" in English, and it is explained in this way in almost all vocabularies and encyclopedic dictionaries of the country (e.g., [23-25]), we could not find another ethnomycological source for the preparation of this flammable substance in the country. However, according to our inquiries, many people (especially in age over 55) are familiar with such usage and in addition, it became clear that some people from the central part of the country cut the fruiting bodies of the fungus in slices and after that soak them in animal urine for some days. Afterwards the soaked slices are dried in the sun and used as kindling during the winter season.

\section{Conclusions}

According to the ethnomycological sources analysed, the usage of mushrooms and lichens in Bulgaria has deep roots in the past and dates back to the Neolithic and Bronze Age. In that time people consumed hallucinogenic fungi during their mysteries. Nowadays this entheogenic use is replaced by utilization of two hallucinogenic mushrooms as a source of recreational drugs, and usage of 5 new species, both autoand allochthonous during the last decades, is documented. All hallucinogenic fungi utilized in the country belong to Basidiomycota. Since centuries, the Bulgarian folk medicine involves Ascomycota (4 lichens) as remedies for treatment of different diseases. Among them the application of Cetraria islandica in Bulgaria in treatment of more than 200 maladies is very impressive. Cetraria and Lobaria pulmonaria are still used by people, mainly in form of modern anticough remedies. In addition to the medicinal uses, the oakmoss is briefly mentioned as a source for perfumery compounds. Basidiomycetes appear as a relatively new group, used in various aspects of fungotherapy and recently 9 macromycetes achieved high public awareness as "exotic," "vital," and "magic" fungi, in spite of the fact that some of the species are common in the country. Some basidiomycetes with tubular hymenophore are used as a source for tinder and kindling.

\section{Conflict of Interests}

The authors declare that there is no conflict of interests regarding the publication of this paper.

\section{References}

[1] M. U. Charaya and R. S. Mehrotra, "From ethnomycology to fungal biotechnology: a historical perspective," in From Ethnomycology to Fungal Biotechnology: Exploiting Fungi from Natural Resources for Novel Products, J. Singh and K. R. Aneja, Eds., pp. 1-10, Springer, 1999.

[2] V. P. Wasson and R. G. Wasson, Mushrooms, Russia and History, Volumes 1 and 2, Pantheon, New York, NY, USA, 1957.

[3] R. Heim, R. Cailleux, R. G. Wasson, and P. Thevenard, Nouvelle Investigations sur les Champignons Hallucinogenes, Museum National d'Histoire Naturelle, Paris, France, 1967.

[4] R. G. Wasson, Soma, Divine Mushroom of Immortality, Harcourt Brace Jovanovich, New York, NY, USA, 1968.
[5] R. G. Wasson, The Wondrous Mushroom: Mycolatry in Mesoamerica, McGraw-Hill, 1980.

[6] G. Guzmán, "New species and new records of Psilocybe from Spain, the U.S.A. and Mexico, and a new case of poisoning by P. barrerae," Documents Mycologiques, vol. 29, no. 116, pp. 41-52, 2000.

[7] G. Samorini, Funghi allucinogeni. Studi etnomicologici, Telesterion, Dozza, Italy, 2001.

[8] G. Guzmán and M. L. Castro, "Observations on some known species of Psilocybe from Spain and description of a new species," Boletín de la Sociedad Micológica de Madrid, vol. 27, pp. 181-187, 2003.

[9] E. Boa, "Wild edible fungi. A global overview of their use and importance to people," Non-Wood Forest Products 17, FAO, 2004.

[10] R. Fernández-Sasia, "Psilocybe hispanica Guzmán, un taxon novedoso en nuestro entorno," Revista Micológica "Errotari", vol. 3, pp. 73-76, 2006.

[11] G. Guzmán, "The hallucinogenic mushrooms: diversity, traditions, use and abuse with special reference to the genus Psilocybe," in Fungi from Different Environments, J. K. Misra and S. K. Deshhmukh, Eds., pp. 256-277, Science Publishers, Enfield, NH, USA, 2009.

[12] G. Zsigmond, Gomba és Hagyomány. Etnomikológiai Tanulmányok, LKG, Pont Kiadó, Sfântu Gheorghe, Romania, 2009.

[13] B. P. Akers, J. F. Ruiz, A. Piper, and C. A. P. Ruck, "A prehistoric mural in Spain depicting neurotropic Psilocybe mushrooms?" Economic Botany, vol. 65, no. 2, pp. 121-128, 2011.

[14] I. Svanberg, Ł. Łuczaj, M. Pardo de-Santayana, and A. Pieroni, "History and current trends of ethnobiological research in Europe," in Ethnobiology, E. N. Anderson, D. Pearsall, E. Hunn, and N. Turner, Eds., chapter 12, pp. 189-212, John Wiley \& Sons, 2011.

[15] G. Guzmán, "New taxonomical and ethnomycological observations on Psilocybe s.s. (Fungi, Basidiomycota, Agaricomycetidae, Agaricales, Strophariaceae) from Mexico, Africa and Spain," Acta Botanica Mexicana, vol. 100, no. 1, pp. 79-106, 2012.

[16] D. Ivanova and D. Ivanov, "Ethnobotanical use of lichens: lichens for food review," Scripta Scientifica Medica, vol. 41, no. 1, pp. 11-16, 2009.

[17] M. P. Stoyneva-Gärtner and B. A. Uzunov, "An ethno biological glance on globalization impact on the traditional use of Algae and Fungi as food in Bulgaria," Journal of Nutrition \& Food Sciences, vol. 5, article 413, 2015.

[18] P. Dimkov, Guide to Natural Healing and Living, vol. 1-3, Publishing House Fakel, 4th edition, 1939.

[19] P. Dimkov, Bulgarian Folk Medicine. Naturopathy and Natural Life, vol. 1, Publishing House of Bulgarian Academy of Science, 1977.

[20] P. Dimkov, Bulgarian Folk Medicine. Naturopathy and Natural Life, vol. 2, Publishing House of Bulgarian Academy of Science, 1978.

[21] P. Dimkov, Bulgarian Folk Medicine. Naturopathy and Natural Life, vol. 3, Publishing House of Bulgarian Academy of Science, 1979.

[22] N. Stoyanov, Guide for Herb-Gathering, Publishing House Zemizdat, Sofia, Bulgaria, 1966.

[23] I. I. Ivanov, I. I. Landzhev, and G. K. Neshev, The Herbs in Bulgaria and Their Use, Publishing House Zemizdat, Sofia, Bulgaria, 1971.

[24] http://www.onlinerechnik.com. 
[25] http://www.ezikov.com.

[26] http://rechnik.info.

[27] G. Georgiev, Medicinal Mushrooms against Cancer and Other Diseases, Publishing House Doktor Natura, 2010.

[28] V. Guerassimova and T. Stoytchev, Scenes Ithyphalliques Rituelles dans la Peinture Monochrome des Grottes sur les Terres Bulgares, vol. 8, Annuaire du Musee National Archeologique, Plovdiv, Bulgaria, 1992.

[29] T. Stoytchev and V. Gerassimova, "Bronze-age regional calendars in monochrome cave paintings in Bulgaria," Annuary of Department of Archaeology-NBU, vol. 1, pp. 8-22, 1994.

[30] S. Draganov and M. Stoyneva, "The attention of Ministry of the Environment. Proposal for announcement of protection of some species algae, fungi and lichens," Ecology, Biology and Biotechnology (Sofia, Bulgaria), vol. 4, pp. 62-64, 1994.

[31] R. Daskalov, Drugs, Publishing House Mishlena, 2006.

[32] V. Moncheva, "The season of magic mushrooms. Hallucinogens-3-cm temptation 17 of the mountain," 2006, Article No 94116, http://www.monitor.bg/.

[33] I. Bakalov, "Sofia residents graze 'magic mushrooms' in the meadows above Govedartsi," 2010, http://e-vestnik.bg/10330.

[34] G. Kamenova, Ancient Curative Recipes. Remedies from Centuries. Reliable Recipes from Generations of Bulgarians, Publishing House Bard, Sofia, Bulgaria, 2015.

[35] http://www.indexfungorum.org.

[36] W. Wirth, M. Hauck, and M. Schultz, Die Flechten Deutschlands: Band 1 und Band 2, Eugen Ulmer, Stuttgart, Germany, 2013.

[37] http://www.ethnobiology.net.

[38] http://www.aaanet.org.

[39] E. Brande, "Mr. E. Brande, on a poisonous species of Agaric," The Medical and Physical Journal: Containing the Earliest Information on Subjects of Medicine, Surgery, Pharmacy, Chemistry and Natural History, vol. 3, pp. 41-44, 1799.

[40] G. Guzmán, "A successful coincidence: the hallucinogenic mushrooms, the genus Psilocybe, the traditions and the development of mycology in Mexico," in Mushroom Biology and Mushroom Products, J. E. Sánchez, M. G. Nieto, F. J. Márquez et al., Eds., pp. 9-14, UAEM, 2002.

[41] F. Bernardino de Sahagún, Historia General de las Cosas de La Nueva España, vol. 2, Alfa, Mexico City, Mexico, 1955.

[42] F. Bernardino de Sahagún, Códice Florentino de la obra Historia General de las Cosas de la Nueva España, Facsimly Copy, Archivo General de la Nación, Mexico City, Mexico, 1979.

[43] R. E. Schultes, "The identifications of teonanácatl, a narcotic basidiomycete of the Aztecs," Botanical Museum Leaflets, Harvard University, vol. 7, pp. 37-55, 1939.

[44] R. Heim, "Les champignons divinatoires utilisés dans les rites des Indies Mazatèques, recueillis au cours de leur premier voyage au Mexique, en 1953, par $\mathrm{M}^{\mathrm{me}}$ Valentina Pavlovna Wasson et M. R. Gordon Wasson," Comptes Rendus de l'Académie des Sciences, vol. 242, pp. 965-968, 1956.

[45] R. G. Wasson, "Seeking the magic mushroom," Life Magazine, New York, vol. 49, no. 19, pp. 100-120, 1957.

[46] G. Guzmán, "Hallucinogenic mushrooms in Mexico: an overview," Economic Botany, vol. 62, no. 3, pp. 404-412, 2008.

[47] C. Kuhn, S. Swartzwelder, and W. Wilson, Buzzed: The Straight Facts about the Most Used and Abused Drugs from Alcohol to Ecstasy, W.W. Norton \& Company, 2003.

[48] G. Samorini, "The oldest representations of hallucinogenic mushrooms in the world (Sahara Desert, 9000-7000 B.P.)," Integration, vol. 2, no. 3, pp. 69-78, 1992.
[49] M. Merlini and A. Velichkov, Eds., Routes and Itineraries from the Virtual Museum of the European Roots, F-MU.S.EU.M. Project, Sofia, Bulgaria, 2009.

[50] A. Arcá, "Magura Cave paintings, Bulgarian rock art," TRACCE Online Rock Art Bulletin 33, 2014.

[51] K. Kirilov, Dedication in Magura, Publishing House Izdavam, 2013.

[52] J. A. Ammirati, J. A. Traquair, and P. A. Horgen, Poisonous Mushrooms of the Northern United States and Canada, University of Minnesota Press, Minneapolis, Minn, USA, 1985.

[53] D. G. Spoerke and B. H. Rumack, Eds., Handbook of Mushroom Poisoning: Diagnosis and Treatment, CRC Press, 1994.

[54] M. Drumeva-Dimcheva, G. Stoychev, and M. Gyosheva, 50 Fungi for Mushroom Lover. Book 2, Publishing House Gea Libris, Sofia, Bulgaria, 1998.

[55] H. Nyberg, "Religious use of hallucinogenic fungi: a comparison between Siberian and Mesoamerican cultures," Karstenia, vol. 32, no. 2, pp. 71-80, 1992.

[56] J. Karadzhov, The Drugs, Publishing House Dilok, 2003.

[57] J. Brough, "Soma and Amanita muscaria," Bulletin of the School of Oriental and African Studies, vol. 34, no. 2, pp. 331-362, 1971.

[58] P. T. Furst, Hallucinogens and Culture, Chandler \& Sharp, 1976.

[59] C. M. Denchev and B. Assyov, "Checklist of the larger basidiomycetes in Bulgaria," Mycotaxon, vol. 111, pp. 279-282, 2010.

[60] P. Stamets, Psilocybin Mushrooms of the World: An Identification Guide, Ten Speed Press, Berkeley, Calif, USA, 1996.

[61] P. P. Wieczorek, D. Witkowska, I. Jasicka-Misiak, A. Poliwoda, M. Oterman, and K. Zielińska, "Bioactive alkaloids of hallucinogenic mushrooms," in Studies in Natural Products Chemistry, Atta-ur-Rahman, Ed., vol. 46, chapter 5, pp. 133-168, Elsevier, 2015.

[62] A. Popnikolov and B. Zhelezova, Flora of Bulgaria. Lichens, Publishing House Narodna Prosveta, Sofia, Bulgaria, 1964.

[63] Y. Motika and B. Zhelezova, "Monographic study of the genus Usnea in Bulgaria," Bulletin de L'Institut Botanique, vol. 10, pp. 67-120, 1962.

[64] O. Gilbert, Lichens, Harper Collins, London, UK, 2000. 

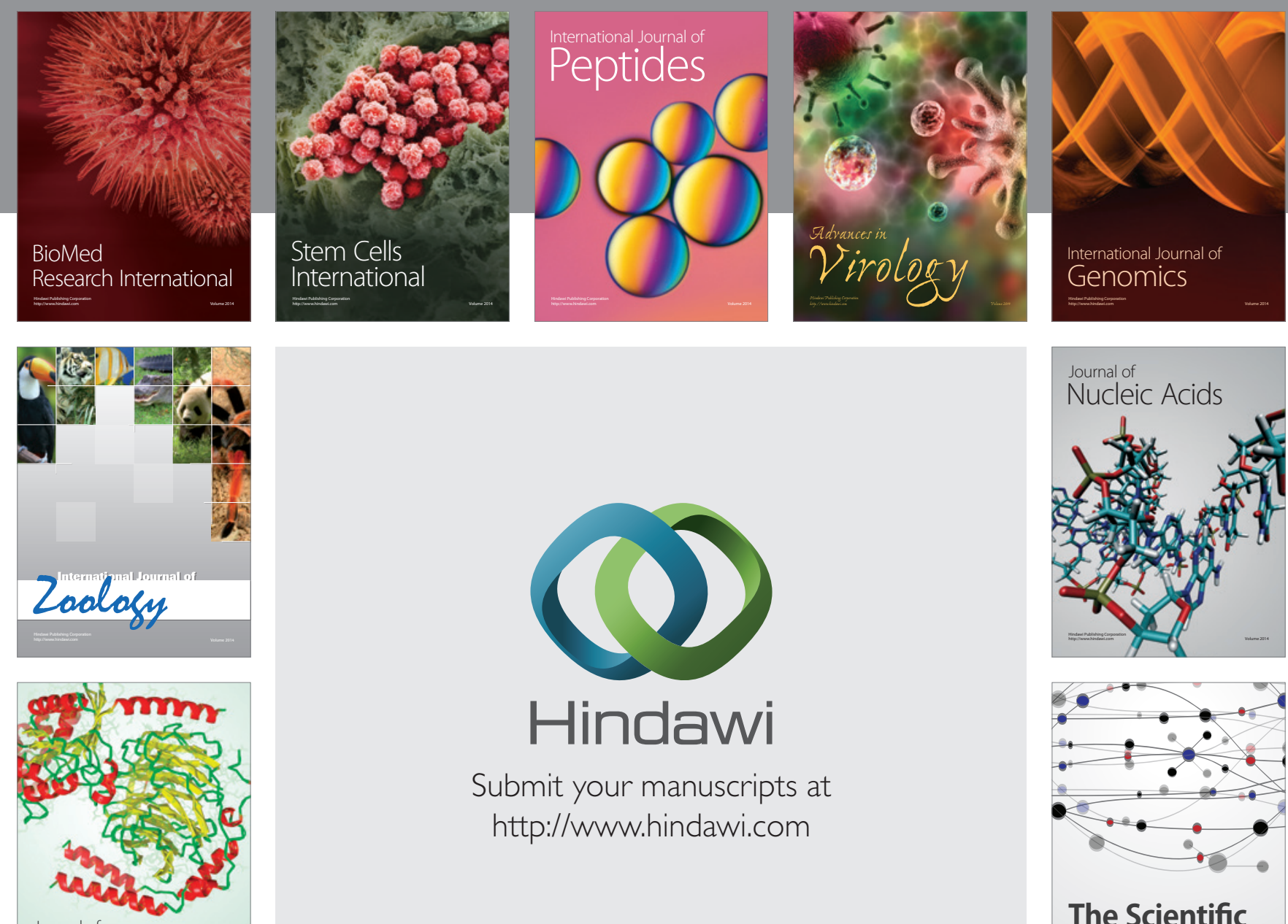

Submit your manuscripts at

http://www.hindawi.com

Journal of
Signal Transduction
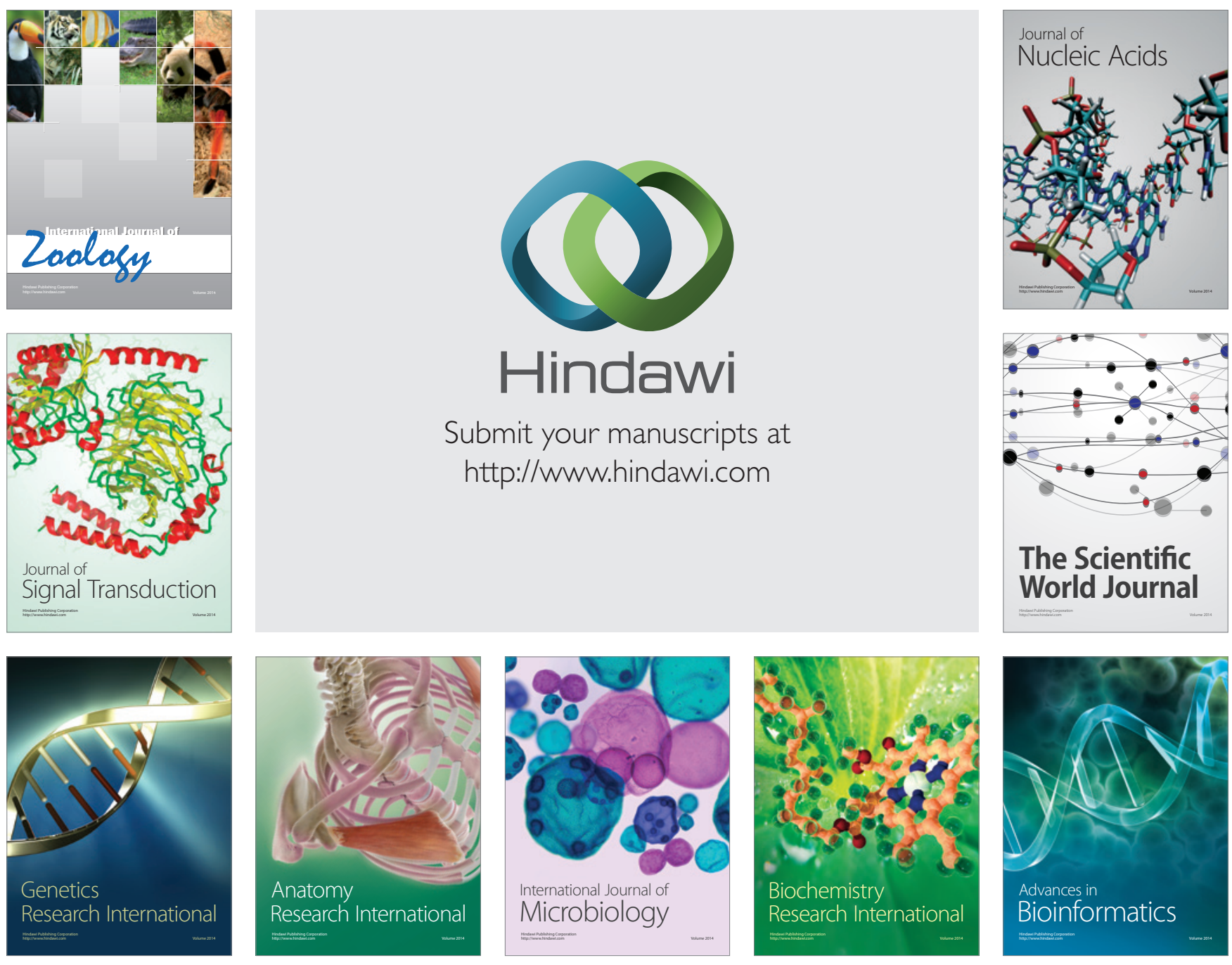

The Scientific World Journal
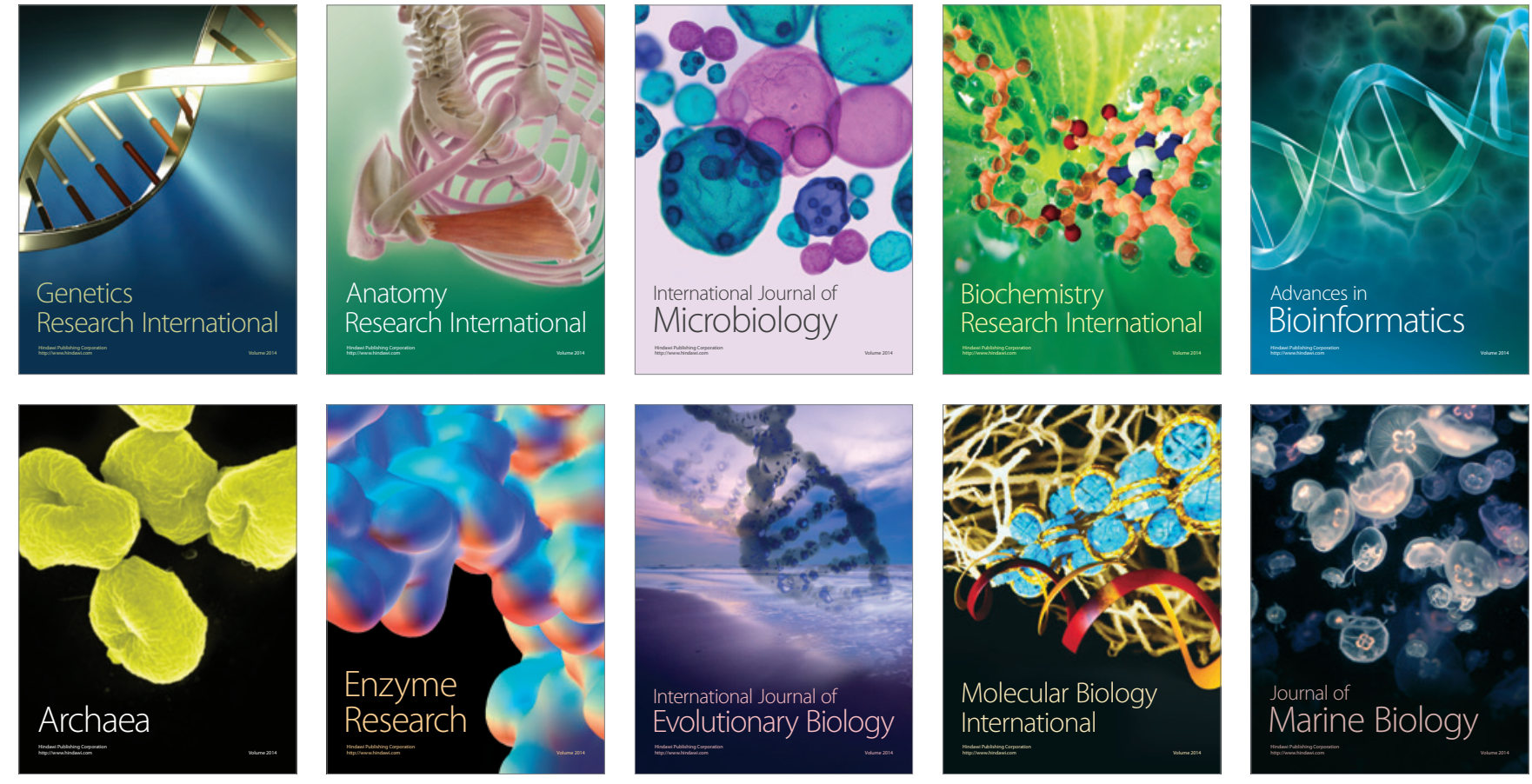